\title{
Redes intelectuales en Repertorio Americano ${ }^{l}$
}

\author{
Angélica López-Plaza \\ Becaria Posdoctoral \\ Universidad Nacional Autónoma \\ México
}

\section{Resumen}

Parte fundamental del proyecto de Joaquín García Monge con su Repertorio Americano fue reunir, en un mismo espacio editorial, a diversos escritores de toda nuestra América. Los textos de estos escritores hicieron de la revista un espacio estratégico para articular y legitimizar un proyecto político y cultural transnacional. En este ensayo propongo realizar un recorrido por algunas de las redes intelectuales que se generaron en torno de Repertorio Americano

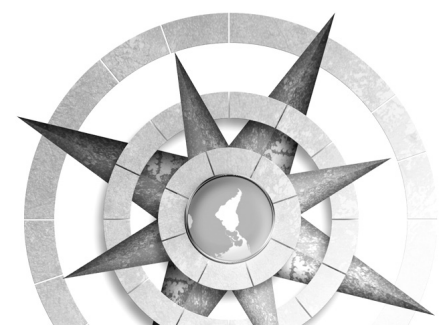

durante la década de los años cuarentas.

Se destacan particularmente el caso de los costarricenses en México, los refugiados españoles en Costa Rica y las colaboraciones de los mexicanos .

Palabras clave: redes intelectuales, Joaquín García Monge, Repertorio Americano, costarricenses en México, refugiados españoles en Costa Rica, Cátedra del Exilio

\section{Abstract}

A primary goal in the editorial project of Joaquin García Monge and his Repertorio Americano was to gather in this journal, different writers from the Americas. The works of these writers made

$1 \mathrm{El}$ presente ensayo es el resultado del proyecto que llevo a cabo como becaria posdoctoral en la Universidad Nacional Autónoma de México, en el Centro de Investigaciones sobre América Latina y el Caribe. También responde a la investigación que desarrollo como investigadora interna en el Proyecto PAPIIT IA400617 "Republicanos españoles en América Latina durante el franquismo, 1939-1975”, de la UNAM. 
the journal become a strategic space to articulate and legitimize a transnational political and cultural project. In this essay I aim to analyze some of the intellectual networks that sprung around the Repertorio Americano during the 1940's. Particularly noteworthy are the Costa Ricans living in Mexico, the Spanish refugees in Costa Rica and the collaborations of Mexicans.

Keywords: Intellectual networks, Joaquín García Monge, Repertorio Americano, Costa Ricans in México, Spanish refugees in Costa Rica, Exile Research Group.

Dirigida por Joaquín García Monge, la revista Repertorio Americano apareció semanalmente en San José, Costa Rica, en 1919 (aunque con periodos irregulares). Salieron aproximadamente mil números entre septiembre de 1919 y mayo de 1958. Fue un proyecto de largo alcance dedicado a la cultura hispánica. Filosofía, literatura, arte, educación y ciencia son algunas de las disciplinas que el semanario incluyó entre sus páginas. Continuadora en cierto modo de Repertorio, revista fundada por Andrés Bello en 1826, la nueva revista tuvo el propósito principal de aglutinar a los escritores americanos en un frente común que enfatizara un tono de alianza hispanoamericana.
En las páginas de la revista encontramos contribuciones de destacados representantes de la vida intelectual y literaria costarricense, por ejemplo: Ricardo Segura, Emilia Prieto, Octavio Jiménez, Mario Sancho y el mismo Joaquín García Monge. También colaboraron escritores del orbe hispanoamericano: Carmen Vilchis Baz, José Vasconcelos, Juan Ramón Jiménez, Pedro Juan Labarthe, Juan Marinello, entre otros. Parte fundamental del proyecto de Joaquín García Monge fue, precisamente, reunir en un mismo espacio editorial a diversos escritores de toda nuestra América. Los textos de estos escritores hicieron de la revista un espacio estratégico para articular y legitimizar un proyecto político y cultural transnacional. ${ }^{2}$ Así lo muestran los ensayos, los poemas, las notas y las cartas que durante treinta y nueve años se publicaron en las páginas de la revista.

En 1944, Joaquín García Monge hizo un balance del trabajo realizado en la revista costarricense, del cual comentó:

2 Según Ligia Carvajal Mena, “[...] con el Repertorio Americano, los costarricenses contaron con un punto de encuentro, un espacio para que todas las personas externaran ideas, inquietudes, denuncias y esperanzas. Por su medio García Monge logró establecer una dinámica de interacción y construcción de una comunidad ideal, supranacional, política con una base hispanoamericana que escribía y a la cual se dirigía la revista”, Revista Estudios, Universidad de Costa Rica, número 20, 2007, p. 148. 
Los hombres de nuestra América se han sentido, lo mismo que los grupos intelectuales, como aislados los unos de los otros. Yo he querido hacer del REPERTORIO un punto de cita, un caluroso rincón del hogar americano en donde todas las inteligencias y todas las ideas encuentren acogida afectuosa y comprensiva. En este rincón se han estrechado las manos los que poco antes mutuamente se desconocían y esto me ha dado el gusto de aquel que como anfitrión, logra reunir en torno de su mesa a los más distinguidos representantes de la nobleza del espíritu. Por largo tiempo el REPERTORIO ha sido perpetuo convivio platónico. El pensamiento hermoso de la mayoría de los pensadores de América ha tenido asiento en el Banquete. ${ }^{3}$

La imagen del banquete evocada por el fundador y editor de la revista revela cuál era el sentido ideológico del semanario. En clara continuación con los discursos nacionalistas del siglo XIX,

3 Joaquín García Monge, "Unidos por la cultura", en Papeles olvidados: polémicas, discursos, escritos oficiales, prólogo, notas y compilación de Fernando Herrera, San José de Costa Rica, Editorial Universidad Estatal a Distancia, 2012, pp. 130 y 131. Discurso que Joaquín García Monge escribió en 1944, -pero no pronunció-, al otorgársele el Premio María Moors Cabot de la Universidad de Columbia.
Joaquín García Monge puso especial énfasis en la corriente americanista y en sus diversas manifestaciones literarias, estéticas y filosóficas. De ahí que Repertorio Americano le diera cohesión a un grupo de intelectuales que clamaban por la transformación política y social de América Latina.

El proyecto de Joaquín García Monge puso en escena los debates políticos y culturales de la época: el hispanoamericanismo, el antiimperialismo y la defensa de los sistemas democráticos. En las páginas de la revista se dieron cita escritores e intelectuales de diversas corrientes políticas e ideológicas -socialistas, anarquistas y revolucionarios- todos reunidos bajo un precepto común: defender la soberanía de los pueblos americanos. Para García Monge, las editoriales -piénsese, por ejemplo, en Ariel y Convivio, colecciones que fundó y dirigió-; y las revistas resultaban fundamentales para canalizar los distintos movimientos estéticos e ideológicos que comenzaban a tener protagonismo en el ámbito hispanoamericano.

Y no menos satisfacción me ha proporcionado el hecho de que todos los escritores de América hayan encontrado en el semanario a mi cargo los justos clamores de sus propias patrias (un 
auditorio, una fe, una esperanza [...]; de que en sus páginas hayan mirado desplegadas todas las gracias de la poesía toda la fuerza del pensamiento de poetas y ensayistas y estadistas de cada una de estas patrias, por la independencia de Puerto Rico y por la americanización de las Guayanas y Malvinas, por ejemplo, se han levantado voces vigorosas en el REPERTORIO, sin diversión odiosa para nadie y sólo sí con un intenso amor por las causas de la libertad. Patrias hemos querido ser, no meros territorios coloniales. Imperialismos, dictaduras y tiranías hallaron en la revista de que soy el editor páginas de combate. Caídas las tiranías aquellas páginas se tornaban en motivo de júbilo y de esperanza en días mejores. ${ }^{4}$

En la década de los años cuarenta y movido por los ideales de justicia y libertad, Joaquín García Monge hace de Repertorio un punto de encuentro para distintos escritores e intelectuales que por diversas razones se hallaban fuera de sus países de origen. Entre estos intelectuales, destacan Vicente Sáenz y Carlos Jinesta, dos costarricenses radicados en México. También se distinguen

4 Ibid.
Víctor Lorz y Lizárraga y Rafael Ruano Riesgo, dos republicanos españoles exiliados en Costa Rica. La confluencia de estos pensadores y científicos en un mismo espacio editorial implicó una constante reflexión sobre temas que los relacionaban de distintas maneras: la situación política de América, la defensa de la Segunda República española y algunas nociones estéticas sobre artistas y escritores del campo cultural hispanoamericano. Asimismo, algunos connotados representantes de la intelectualidad mexicana ayudaron a fortalecer la red que tejía Repertorio Americano.

En este orden de ideas, propongo realizar un recorrido por algunas de las redes intelectuales que se generaron en torno de Repertorio Americano durante la década de los años cuarenta. Se destacan particularmente el caso de los costarricenses en México, los refugiados españoles en Costa Rica y las colaboraciones de los mexicanos.

\section{Las colaboraciones de dos costarricenses radicados en México}

\section{El caso de Vicente Sáenz}

El exilio costarricense en México durante la década de 1940, (piénsese en José Figueres, Vicente Sáenz, María Isabel Carvajal, sólo por mencionar a 
algunos) generó lazos políticos y culturales con algunas de las figuras más importantes del campo intelectual mexicano. En muchos de los casos, los exiliados costarricenses se dedicaron a convocar reuniones y actividades con el fin de democratizar la vida política de la región centroamericana y caribeña. La historiografía mexicana ha dado cuenta de algunas de las características de este exilio centroamericano y de su participación en distintas organizaciones políticas. ${ }^{5}$ Ahora bien, cabría preguntarse si los exiliados costarricenses mantuvieron contacto con intelectuales y políticos de su país de origen, cuáles fueron los medios utilizados para mantener esa comunicación y qué temas trataron. Entender esta faceta del exilio costarricense es básico para iluminar un proceso que generalmente se ha analizado desde la perspectiva mexicana, esto es, los detalles de este exilio en el país de acogida.

Uno de los costarricenses exiliados en México que más influyó en la escena pública centroamericana fue, sin duda, el periodista y profesor Vicente Sáenz. La figura de Sáenz resulta fundamental para comprender los avatares políticos

5 Sobre este tema, véase Laura Beatriz Moreno Rodríguez y José Francisco Mejía Flores, "El exilio costarricense en México en la década de 1940", en Cuadernos Americanos, núm. 152, México, 2015/2, pp. 51-73. del istmo durante el siglo XX. Gracias a su formación académica y a su sólida experiencia periodística, Vicente Sáenz logró tener un espacio muy visible en el ámbito intelectual y político hispanoamericano. La experiencia que adquirió durante sus viajes y estancias en Estados Unidos, España, Centroamérica y México fue elemental para la concepción de su propio método histórico de análisis y de escritura. ${ }^{6}$

Vicente Sáenz llegó a México el 30 de julio de 1940. Según el Registro Nacional de Extranjeros (RNE), el motivo de su visita fue tomar apuntes para escribir un libro sobre México. Sin embargo, su visita se prolongó, y desde tierras mexicanas conformó la Unión Democrática Centroamericana (udc), organización de intelectuales y políticos exiliados que luchaban contra el imperialismo y los regímenes totalitarios en Centroamérica ${ }^{7}$ También ejerció como periodista y profesor de historia en diversas universidades. Y aunque su salida de Costa Rica fue motivada por las diferencias políticas que mantuvo con el gobierno de Rafael

6 Sobre la obra de Vicente Sáenz véase la colección dirigida por Mario Oliva Medina: Tras las huellas de Vicente Sáenz; Expediente 1533: el presidio de Vicente Sáenz en 1939; Rompiendo cadenas, las del imperialismo norteamericano en Centroamérica; Traidores y déspotas en Centroamérica; El grito del dolor y otras causas; España heroica publicada por Editoriales Universitarias Públicas Costarricenses (edupuc).

7 L. B. Rodríguez y J. F. Mejía Flores, op. cit., p. 61. 
Ángel Calderón Guardia (1940-1944) su vocación de activista social, de promotor de la educación y de reformista social continuó durante su exilio.

Desde el exilio, Vicente Sáenz procuró mantener un contacto con la sociedad costarricense a través de la revista del que fuera uno de sus maestros en el Liceo de Costa Rica, Joaquín García Monge. Las contribuciones del exiliado en Repertorio Americano se pueden dividir en dos temas principales: el apoyo a la Segunda República española y la situación política de Centroamérica y el Caribe. Algunas de estas colaboraciones son inéditas y otras son envíos que el autor hizo llegar a su homónimo costarricense; cada una de ellas está directamente relacionada con dos libros fundamentales del pensamiento de Vicente Sáenz; me refiero a su obra magna: Rompiendo cadenas (1933) y España heroica (1938).

En "Perturbación de la paz en Centro América y en el Caribe", ponencia publicada en febrero de 1950, Vicente Sáe$\mathrm{nz}$ comenta ante el Comité Interamericano de Paz reunido en México acerca de la situación política en la zona del istmo. La ponencia resume en buena medida el discurso antiimperialista que Sáenz había articulado en varios de sus libros. Al referirse a las dictaduras en
Centroamérica, denuncia el apoyo que Estados Unidos le brindaba a algunos regímenes dictatoriales de la zona:

No dispongan de aviones, de tanques, de medios económicos, de relaciones internacionales los hombres que ametrallan a sus conciudadanos, y sin intervención de nadie de afuera se vendrán al suelo de cabeza. Cortar relaciones con ellos es lo que se pide -sin intervenir en sus asuntos domésticos- como se haría con vecinos crapulosos, a cuya misma mesa no hay razón ética que nos obligue a tomar asiento. ${ }^{8}$

El ensayo culmina con la firma de Joaquín García Monge y Emilia Prieto, presidente y secretaria, respectivamente, del Congreso Pro Paz de Costa Rica. Y se añade la siguiente nota firmada por la artista costarricense: "le delegación de Costa Rica, recogiendo el clamor del pueblo costarricense, que vive bajo el temor de una dictadura, acoge y apoya esta ponencia sobre el aislamiento de dictaduras". 9 Conviene recordar que durante la década de los años cincuenta los comunistas y sus aliados fueron perseguidos, y algunos vivieron en la

8 Vicente Sáenz, "Perturbación de la paz en Centro América y en el Caribe", en Repertorio Americano, núm. 1104, 1950, p. 69.

$9 \quad$ Ibid. 
clandestinidad. De ahí que resulte fundamental encontrar en un mismo manifiesto las firmas de Vicente Sáenz, de Joaquín García Monge y de Emilia Prieto, comunista perseguida a partir del cambio político que se generó durante la Guerra Civil de 1948.

La publicación de la ponencia en Repertorio Americano da cuenta de la necesidad de promover los movimientos anti-colonialistas de la zona centroamericana y caribeña. En diversas ocasiones, Joaquín García Monge expresó el impacto que los medios de comunicación, la escena pública y cultural debían tener en los procesos políticos y sociales de la región. Al respecto, comentaba: "Hay que oponerse a la funesta influencia concebida por los intereses del capitalismo, de la política y de la Iglesia en el deporte, el cine, la radio y la revista (cierto deporte, cierto cine, ciertas revistas, etc.). En nuestra América estos recursos los maneja con habilidad el imperialismo yanqui y los jesuitas a su servicio. Domestican, con eso, y hacen estúpida a nuestra juventud en sectores poderosos". ${ }^{10}$

10 Joaquín García Monge, carta dirigida al secretario del Congreso Mundial de la Paz en París, 17 de abril de 1949, en Cartas selectas de Joaquin García Monge, selección e introducción de Eugenio García Carrillo, San José de Costa Rica, Editorial Costa Rica, 1983, p. 147.
El resultado de esta interacción entre intelectuales comprometidos con el devenir político y social de Centroamérica y los espacios de difusión fue el surgimiento de nuevas redes de sociabilidad. Los exiliados costarricenses se verán en la necesidad de encontrar puntos de encuentro con intelectuales y artistas de su país de origen para así consolidar sus propuestas políticas e ideológicas. En este sentido, Repertorio Americano fungió como un espacio simbólico en el que se dieron cita exiliados, perseguidos y defensores de los derechos democráticos de Latinoamérica.

Con todo, en las páginas de la revista no sólo se difundieron los ideales unionistas y antiimperiales de diversos sectores del campo intelectual costarricense exiliado en México, sino que, además, se divulgaron conflictos en los que los mismos exiliados fueron protagonistas. Un buen ejemplo es la carta que Vicente Sáenz envío a García Monge el 8 de abril de 1947. La misiva va dirigida a Rodrigo de Llano, director general de Excélsior, y al semanario nocturno Últimas Noticias.

En la carta, el costarricense se defiende de los falsos ataques que Rodrigo de Llano y la Unión Nacional Sinarquista profirieron contra la Unión Democrática Centroamericana. El punto de ataque 
eran los supuestos "conspiradores rojos" que formaban el Consejo Ejecutivo de la organización: "Sobre el particular puedo y es deber mío aclarar que quienes incluso con el aplauso de Excélsior, han laborado desde México contra los regímenes totalitarios de Ubico, Hernández Martínez -ya caídos- y los que aún superviven en el Istmo, son personas tan conocidas y apreciadas en esta capital que con dar solamente sus nombres se viene abajo toda la maniobra”."1

Pese a que la UDC fue una organización o movimiento tolerado en el marco del sistema político mexicano, la carta da cuenta de las discrepancias y ataques que sufrieron los exiliados centroamericanos por parte de algunos sectores de la política mexicana. Sin duda, textos de carácter personal, como la carta de Sáenz, iluminan una parte del proceso político y social vivido por los exiliados costarricenses en México.

Vicente Sáenz también apoyó la causa de la Segunda República española; en 1936 fue a España como invitado a un congreso de escritores hispánicos. Allí le sorprendió el inicio de la Guerra Civil, conflicto que hará que su estancia se prolongue por varios meses y que consagre por completo sus afanes como

11 Vicente Sáenz, "Pido la palabra”, en Repertorio Americano, núm. 1913, 1947, p. 27. escritor y propagandista a la causa republicana. Resultado de esta experiencia es el libro España heroica, publicado en 1938. "El pueblo español se salva ante la historia”, artículo publicado en 1941 en la revista costarricense, que es una muestra del compromiso que Sáenz mantuvo con la causa republicana: "por lo que a España se refiere, por lo de ayer, por lo de hoy, por lo de siempre, continúa siendo la nación de más trágico destino. En ello está su grandeza. Y en ello está su heroicidad. Y también la situación de lo que será otra vez república democrática de trabajadores". ${ }^{2}$ A lo largo del texto Sáenz insiste una y otra vez en la importancia de la tragedia española para el futuro de la política internacional de Latinoamérica. Sin lugar a dudas, Sáenz formaba parte de los escritores y políticos que ejercieron una influencia importante en el pensamiento latinoamericano del siglo XX.

\section{El caso de Carlos Jinesta}

Carlos Jinesta Muñoz fue otro de los colaboradores costarricenses que contribuyeron a fortalecer la red intelectual que Joaquín García Monge tejió en torno de su Repertorio. Jinesta Muñoz viajó a México en calidad de representante diplomático. Durante los veinte años

12 Vicente Sáenz, "El pueblo español se salva ante la historia”, en Repertorio Americano, núm. 907, 1941, p. 44. 
que reside en México, el costarricense ejerció distintos cargos políticos: de 1942 a 1948 fue nombrado embajador de Costa Rica en México por el presidente Rafael Calderón Guardia y ratificado por el próximo presidente costarricense, Teodoro Picado.

Al término de su representación diplomática, ejerció como asesor especial del presidente mexicano Miguel Alemán. El intercambio político que el embajador sostuvo con varios dirigentes de las esferas mexicanas, costarricense y soviética durante la década de los años cuarenta es un suceso que todavía presenta ciertas interrogantes y opacidades.

Sin embargo, sabemos que Carlos Jinesta conoció a Constantino Oumansky, embajador soviético en México. El objetivo principal del encuentro consistió en restablecer las relaciones diplomáticas entre Costa Rica y la URSS. En 1944, los representantes diplomáticos acordaron establecer los vínculos oficiales entre los dos países. ${ }^{13}$ Con todo, los vínculos entre las dos naciones no prosperaron debido al fatal accidente de que fue víctima el embajador soviético. Eduardo Mora Valverde, que en ese momento era estudiante y vivía en México, comenta el suceso:

13 Pedro González Olvera, "Amistad y buenos oficios”, en La Nación, 29 de agosto de 2010, http://www.nacion.com/archivo/Amistad-buenos-oficios_0_1143685670.html.
Con el abogado Fernando Brenes Argüello y la escritora Yolanda Oreamuno, en la noche visité al Embajador de Costa Rica, don Carlos Jinesta Muñoz. Se encontraba muy dolido y tenso cuando nos dijo:

-El Embajador Oumnaski me invitó a acompañarlo a Costa Rica. Pedí autorización a la Cancillería y ésta me la dio. Salí temprano de mi casa y me dirigí al Aeropuerto Militar, pues el avión era propiedad del Ejército. Lo había facilitado el General Lázaro Cárdenas, Ministro de Guerra. En la puerta me recibió supuestamente un funcionario y me dijo que la nave acababa de salir. Para mí fue extraño pues me había presentado unos minutos antes de la hora programada. Regresé contrariado a la Embajada. Ya en ella me enteré del crimen.

Esas fueron sus palabras casi textuales. Después de una pausa que ninguno se atrevió a cortar nos volvió a ver y agregó:

-No les interesaba asesinarme. ${ }^{14}$

14 Fernando Soto Harrison, Qué pasó en los años cuarenta, San José de Costa Rica, Editorial Universidad Estatal a Distancia, p. 125. 
El accidente no pasó desapercibido para la intelectualidad mexicana y costarricense. El escritor Ermilo Abreu Gómez publicó en Repertorio Americano una nota necrológica sobre la muerte del embajador soviético. El 15 de mayo de 1945 se publicó en la revista la nota titulada "Constantino A. Oumansky". El autor destaca la importancia de la figura del embajador en México:

Pocas veces tuve la honra de hablar con Oumansky; pero, de cada entrevista, desprendía la precisa seguridad de que trataba con uno de los más capaces y más sinceros amigos de México. Oumansky estaba atento al desenvolvimiento de nuestra vida. Le interesaban nuestras vicisitudes políticas, tanto como sociales y culturales. Con mirada serena y perspicaz quiso alcanzar el sentido de nuestra existencia. ${ }^{15}$

Este lamentable accidente reunió de manera simbólica a la intelectualidad mexicana y costarricense en un mismo espacio editorial. Con todo, la trama política que rodea al costarricense contrasta significativamente con su faceta literaria. Además de embajador, Jinesta Muñoz también fue un prolífico escri-

15 Ermilo Abreu Gómez, "Constantino A. Oumansky”, en Repertorio Americano, núm. 988, mayo de 1945, p. 337. tor. En México formó parte del círculo de intelectuales integrado por José Vasconcelos, Alfonso Reyes y Carlos Pellicer. En tierras aztecas también publicó varios artículos historiográficos, cuentos, crónicas y una novela. Entre los textos más significativos destacan: Rubén Dario en Costa Rica (1944), Mar y pensamiento (1947), Bronces de México (1949), Evocación de Hidalgo: pluma y lápiz de México (1951) y La gran ciudad (1957).

El embajador publicó en Repertorio Americano una de las biografías que aparecerá en su libro Bronces de México. El 27 de noviembre de 1943 se incluyó la nota titulada "Diego de Rivera". La breve reseña exalta la capacidad que tiene el pintor para representar las clases más desventajadas de la sociedad mexicana. Para Carlos Jinesta, las inquietudes del pintor son las "auténticas inquietudes democráticas" y "pone su pincel al servicio de la Humanidad": "Se le acusa de que su faena alienta el izquierdismo. Sin embargo, nosotros vemos en él solamente al defensor del minero; al que clama sin tregua por la bienandanza de la gente de sarape y huaraches; al que pide para el trabajador buen pan y mejor libro; al que pide para los pobres del globo, temeroso de infinito y de Dios, más justicia y más caridad ${ }^{16}$.

16 Carlos Jinesta, “Diego de Rivera”, en Repertorio Americano, núm. 965, 1943, p. 297. 
Figura 1.

Carlos Jinesta, Bronces de México, Certamen Cultural, México, 1949.

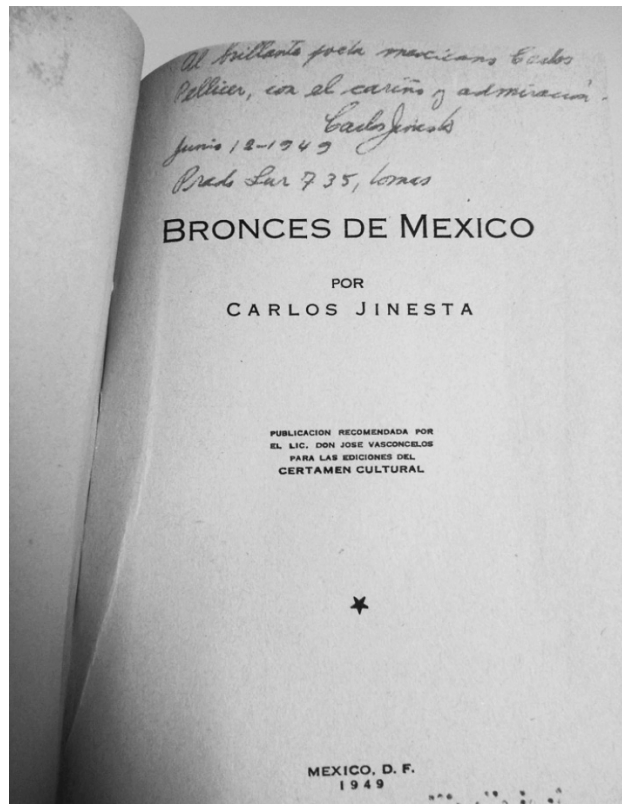

Fuente: Biblioteca Daniel Cosío Villegas de El Colegio de México.

La literatura y el arte mexicanos no fueron las únicas disciplinas que Carlos Jinesta elogió. También se solidarizó con el gobierno y expresó su sentir en un programa radial. El 20 de junio de 1942, publicó en Repertorio Americano la nota titulada "Unas palabras en México. 18 de mayo de 1942: hora dedicada a Costa Rica”. En su emisión radial, Jinesta hizo un balance de las similitudes que compartían las dos naciones:
En México y Costa Rica hay marcadas similitudes por sus conquistas sociales, por su culto a la tradición y a las reverberaciones de su historia, por su estructura medularmente democrática, y por su amor a la justicia y a las luchas libertarias, que son las luchas limpias del decoro humano. En la fisonomía moral del Continente, en constante mensaje espiritual, como proyección de una identidad suprema de bien y unidad cívica, en consorcio gallardo, se destacan México y Costa Rica, compartiendo sus fatigas y ternuras. ${ }^{17}$

Hay que señalar la importancia que Repertorio Americano tuvo para la difusión de ideas y conceptos de fraternidad política y cultural entre los pueblos latinoamericanos. Esta ideología explica por qué en un mismo espacio editorial aparecen figuras tan distantes entre sí, tales como el exiliado Vicente Sáenz y el diplomático Carlos Jinesta. Pese a que los dos escritores militaban en partidos políticos distintos, ambos pregonaban la libertad y la justicia de los pueblos americanos.

17 Carlos Jinesta, "Unas palabras en México,18 de mayo de 1942: hora dedicada a Costa Rica”, en Repertorio Americano, núm. 940, 1942, p. 180. 
En este punto, cabría destacar que el gobierno y la intelectualidad mexicana no sólo acogieron al exilio costarricense y a sus diplomáticos, sino que, también, se proclamaron ante las injusticias vividas por los propios costarricenses en su país natal. Éste es el caso del encarcelamiento de Carlos Luis Sáenz en la Penitenciaría de San José. Joaquín García Monge publicó en las páginas de Repertorio Americano una nota de los mexicanos que estaban a favor de la causa del poeta costarricense. A la nota precede una introducción presumiblemente escrita por el fundador de la revista, Carlos Luis Sáenz, uno de los buenos poetas y profesores de Costa Rica. Por divergencias políticas, ha pasó tres meses en la Penitenciaría de San José de Costa Rica. (Opinar con independencia, sigue siendo un delito para la lívido mandadis que padece el mundo). ${ }^{18}$

Diversos escritores, pintores, músicos y profesores mexicanos suscribieron la nota titulada "Habla México...", que tiene como objetivo solicitar la excarcelación del poeta costarricense. Entre las figuras que firmaron la petición se encuentran: Alfonso Reyes, Ermilo Abreu Gómez, Rafael Solana, Efraín Huerta, Andrés Henestrosa, Diego Rivera, David Alfaro Siqueiros, Julio Prieto, Marta Asúnsolo, Lola Álvarez Bravo, entre

18 Anónimo, "Habla México...", en Repertorio Americano, núm. 1068, 1948, p. 265. otros. El espacio editorial dedicado a Carlos Luis Sáenz culmina con la publicación de varios de sus poemas, algunos inéditos. A este respecto, conviene citar en extenso "La ventana":

Tienen, al preso, una celda en la prisión que lo guarda; la celda, en el muro helado, abre, al cielo, una ventana.

El cielo libre, a los libres busca, sostiene y ampara y asi en la abertura estrecha su presencia nunca falta.

En la noche de la lluvia su oscuridad dice al alma

el fiero temple, el vigor que la tempestad entraña.

Es luz de azucena vivía al vivo toque de diana; flor de luz, que alegra y viste el color de la esperanza. Suena el tambor militar, las puertas están cerradas; en oro de sol reluce para el preso, la ventana.

Si afuera marchan fusiles y negativas espadas en la celda el preso tiene su frente en la luz sin mancha.

La tarde, limpia, en azul, prende, al preso, estrella clara en decoración austera 
a sus no vertidas lágrimas.

O gris, con niebla de tul la recoge, madre blanca, la tristeza en el suspiro por su niño y por su casa.

Toca, el corneta, la queda; suenen férreas las aldabas; el reflector del fortin enciende su luz amarga.

El preso mira la sombra y al relámpago que abrasa ve surgir de la tiniebla toda la enorme montaña.

Y se vuelve a su rincón en la celda que lo aguarda a forjar con pensamiento el relámpago de su alma. 9 de marzo de $1948^{19}$.

Sin lugar a dudas, el fundador y editor de la revista logró su cometido de hacer de Repertorio Americano un "punto de cita”, el rincón del hogar americano”, y sobre todo, el lugar de difusión y lucha para las causas justas.

19 Carlos Luis Sáenz, "La ventana”, en Repertorio Americano, núm. 1068, 1948, pp. 265 y 266.

\section{Las colaboraciones de dos republicanos españoles exiliados en Costa Rica}

En las páginas de la revista también encontramos colaboraciones de destacados representantes de la vida intelectual de España, por ejemplo: Miguel de Unamuno, José Ortega y Gasset, Juan Ramón Jiménez, José Bergamín. Asimismo, hallamos trabajos de varios republicanos españoles exiliados en Costa Rica. De hecho, la presencia de los peninsulares en el semanario no se limita únicamente a sus contribuciones, también ejercieron un papel fundamental en su producción y confección. Avelino Alsina y José Borrasé, catalanes residentes en Costa Rica desde principios del siglo $\mathrm{xx}$, fueron los impresores que se ocuparon de la edición de cada uno de los números. ${ }^{20}$

Ahora bien, el detonante que contribuyó a consolidar la cultura hispánica vertida en la revista fue el inicio de la Guerra Civil española (1936-1939). El tema de España, desde el comienzo del conflicto bélico, tuvo un notable auge entre los escritores agrupados en torno a Repertorio Americano. Sus páginas contienen manifiestos, poemas, ensayos y reflexiones políticas de autores es-

20 Véase Mario Oliva Medina, "Historia de Repertorio Americano (1919-1958)”, en Revista de Comunicación, vol. 17, año 29, 2008, pp. 31-43. 
pañoles y latinoamericanos a favor de la Segunda República; abundan también, los homenajes a Federico García Lorca, a Antonio Machado y al Quijote de Cervantes. Entre los costarricenses que delinearon las dimensiones éticas del conflicto español están la poética de Carlos Luis Sáenz y Ricardo Segura, y el ensayo político de Mario Sancha y Vicente Sáe$\mathrm{nz},{ }^{21}$ sólo por mencionar algunos.

Repertorio Americano se convirtió en el órgano de difusión de la causa republicana española en un ambiente político y social muy poco favorable. El gobierno costarricense presidido por León Cortés (1936-1940), de ideología conservadora y anticomunista, ofreció una marcada dualidad entre la posición neutral exhibida de cara al sistema internacional y las simpatías y apoyo que a nivel nacional mostró por los franquistas. ${ }^{22}$ Asimismo diversos grupos católicos costarricenses se mostraron activa y apasionadamente en favor del general Francisco Franco. En la revista se registró la actitud que el gobierno mostró hacia la ayuda diplomática que algunos

21 Véase Mario Oliva Medina, Los intelectuales y las letras centroamericanas sobre la Guerra Civil española, México, CIALC-UNAM, 2008.

22 Rosa María Pardo Sanz ha estudiado con detenimiento la postura del gobierno costarricense a favor del franquismo en el artículo titulado "América Latina y la Guerra Civil española. Costa Rica: un estudio de caso", en Espacio, Tiempo y Forma, t. 3, 1990, pp. 155-176. países latinoamericanos brindaron a los españoles. A este respecto, sobresale el incidente diplomático chileno-español.

En plena contienda bélica, la embajada chilena en Madrid acogió a diecisiete españoles republicanos que se vieron amenazados por los sublevados. Desde suelo peninsular, la embajada solicitó ayuda internacional para evacuar a los refugiados. Ante ello, el gobierno de Costa Rica guardó silencio. Edgar Odio González comentó en las páginas de la revista el sensible desacierto del gobierno de León Cortés: "por no intervenir en los asuntos de España, se abstiene de pronunciarse sobre los refugiados republicanos en la Embajada de Chile en Madrid". ${ }^{23}$ Con todo, y pese a la postura oficial del gobierno, la solidaridad hacia las gestiones diplomáticas chilenas no se hizo esperar: "Estamos con Chile porque Chile defiende la decencia. El mundo dirá un día que fue la Embajada Chilena en Madrid en donde se dio el primer grito a favor de la cruzada por la decencia". ${ }^{24} \mathrm{El}$ silencio del presidente León Cortés a este respecto correspondió al apoyo que ya en abril de 1939 había brindado al general Franco.

23 Edgar Odio González, "Un sensible desacierto del Gobierno de Costa Rica, frente al incidente diplomático chileno-español", en Repertorio Americano, núm. 872, 1939, pp. 244 y 245.

24 Juan del Camino, "Estamos con la Buena causa, que es la de Chile, desde luego", en Repertorio Americano, número 873, 1939, p. 272. 
Una vez concluida la Guerra Civil española, el gobierno costarricense incrementó la política a favor del franquismo. En 1940, el ministro de Relaciones Exteriores de Costa Rica manifestó su negativa a recibir refugiados republicanos:

El gobierno ha seguido, en materia de inmigración, una política definida y rígida en lo que se refiere a la inmigración inconveniente e indeseable y, en consecuencia, habrá que aplicarla inflexiblemente ante cualquier intento que se haga para el ingreso en el país de los emigrados españoles poco deseables por diversos conceptos. ${ }^{25}$

La declaración da cuenta de la postura oficial que mantuvo el gobierno con respecto al asilo de los republicanos españoles. Sin embargo, la política exterior del gobierno costarricense presentó ciertas fisuras. Durante la década de 1940, llegaron a suelo costarricense refugiados españoles con diversos perfiles: académicos, profesionales y políticos. Entre las figuras más destacadas encontramos al biólogo Rafael de Buen Lozano, al profesor y agrónomo Víctor Lorz y Lizárraga y el médico Rafael Rua-

25 Rosa María Pardo Sanz, "América Latina y la Guerra Civil española. Costa Rica: un estudio de caso", en Espacio, Tiempo y Forma, t. 3, 1990, pp. $155-176$ no Riesgo. La travesía de estas personas en la vida cultural quedó plasmada en las páginas de Repertorio Americano.

Víctor Lorz y Lizárraga fue el republicano español, refugiado en Costa Rica antes de que concluyera el conflicto bélico, que con mayor conciencia crítica se dedicó a reflexionar sobre la causa republicana y las consecuencias del franquismo. Las reflexiones que hizo el profesor y agrónomo español corresponden a dos propósitos fundamentales: primero, ofrecer una interpretación de la Guerra Civil desde una perspectiva anticlerical; segundo, comentar la situación de España en el marco de la política internacional. Cada una de las entregas que Víctor Lorz y Lizárraga hizo a la revista se distinguió por su tono crítico e incisivo.

"Al vagar de una pluma bohemia", "Divagaciones de una pluma errante" y "Ocios mentales" son los tres títulos que reúnen casi todas las colaboraciones del profesor español en Repertorio Americano. Los títulos caracterizan en buena medida la identidad del que escribe: un refugiado político que plantea su escritura como una errancia. Así pues, el acto de escribir representa un lugar privilegiado de indagación sobre la propia identidad. Con todo, la metáfora del deambular de la escritura se 
contrapone a la necesidad que tiene el escritor de aferrarse a España. En una carta que encabeza uno de sus ensayos, Víctor Lorz explicaba a Joaquín García Monge cuáles habían sido las razones para la elección del título: "Como usted verá, mi pluma es de marca bohemia. Va de acá para allá; sin domicilio de tareas fijo; posándose en todo lo que encuentra, como una mariposa de acero; pero, ensartando en sus puntas todos los bichos que encuentra a su paso", ${ }^{26}$

Sin embargo, la principal punta de lanza de la crítica de Víctor Lorz iba dirigida a la injerencia que tuvo la Iglesia Católica en el conflicto español. Un mes antes de que concluyera la Guerra Civil, el profesor denunciaba la Falange española como principal responsable de los sangrientos hechos ocurridos en la península:

En esta hora terrible, el crimen y los veinte dineros de Judas, están con ellos. Ellos beben, engordan y ríen, mientras nosotros, hijos de la ley, tenemos el alma acongojada y desgarrada por el dolor infinito de nuestra santa España. Pero sepan los obispos y los frailucos politiqueros, que la República española, que no ha hecho mal

26 Víctor Lorz y Lizárraga, "Al vagar de una pluma bohemia”, en Repertorio Americano, núm. 869, 1939, pp. 196 y 197. a nadie ha de ser terriblemente vengada. Y que, algún día, la han de llamar a gritos para que vuelva. Pero ya no volverá tan mansa con los obispos y los frailes politiqueros. ¡La sangre de dos millones de seres humanos, no se derrama en vano! La España que venga no será la vuestra. La que vosotros soñasteis, al echarnos en brazos de esos forajidos inconmensurables de la falange española. ${ }^{27}$

Las declaraciones de Victor Lorz responden a la postura anticristiana que tomó la alta jerarquía de la Iglesia Católica al apoyar el levantamiento militar del general Franco. Recuérdese que las reformas discutidas en el escenario de las Cortes Constituyentes en los últimos meses de 1931, particularmente las cláusulas dirigidas al sector religioso -aquellas que declaraban la no confesionalidad del Estado, eliminaban la financiación del clero, introducían el matrimonio civil y el divorcio, y prohibían el ejercicio de la enseñanza a las órdenes religiosas, entre otras- provocaron una oleada de reacciones adversas al régimen. Durante los primeros años del gobierno republicano, se hizo patente el fracaso de la Iglesia y de algunos de sus ministros

27 Víctor Lorz y Lizárraga, "Para que se rasque", en Repertorio Americano, núm. 868, 1939, p. 187. 
para comprender los problemas sociales y los nuevos cambios en materia política y económica.

La posición política de Víctor Lorz y Lizárraga tuvo, durante la década de los cuarenta, importantes transformaciones. Sus colaboraciones en la revista fueron respuestas generalmente coyunturales para intentar orientar la visión que se tenía en el exilio de la problemática de España. De modo que en sus reflexiones acerca del antifranquismo también tuvo presente el caso de América Latina.

Durante el primer año del exilio republicano español en Centroamérica, el falangismo cobró un auge insospechado. El apoyo de sectores conservadores fue decisivo para la difusión de las ideas imperiales del grupo pro franquista. Entre las personalidades costarricenses que destacaron por su apoyo a los falangistas encontramos a J. N. Pinaud, director de La Tribuna, y a D. Rafael Soley, titular del diario Novedades, ambos vinculados al Comité Patriótico Español. Víctor Lorz hizo referencia a estos hechos:

Pero es una insigne torpeza agitar aquellos temas en América, ya que, al trasluz de la retórica falangista, se adivina la intención de sembrar el problema sudeté en el suelo americano, como anticipo de la cosecha política que advendría después: incorporación de América a España.

A mí no me extraña que, en la España nazi, donde no hay libertad para nada, la haya, no obstante, para hablar descaradamente de imperio. Lo que no alcanzo a comprender es, que América se preste a ser un ateneo en que se ventile alegremente el problema sudeté de España. Esto es un abuso de la hospitalidad que debía ser resuelto por la policía con un plazo de veinticuatro horas.

El alma de América no está cerrada para nadie. Tampoco está abierta para uno solo. Antena levantada en los espacios libres, recoge de todos los rumbos de la rosa náutica el Alma Universal. ${ }^{28}$

No sólo Víctor Lorz se expresó acerca del franquismo en Latinoamérica, también el biólogo y oceanógrafo español Rafael de Buen Lozano publicó en la revista un ensayo sobre los acontecimientos políticos que a nivel internacional se dirimían. El devenir de la Segunda Guerra Mundial y la posición neutral

28 Víctor Lorz y Lizárraga, "Las golondrinas de Bécquer”, en Repertorio Americano, número 933, 1942, pp. 70 y 71. 
que la mayoría de los países latinoamericanos tuvo durante los primeros años del conflicto bélico fueron motivos de reflexión para los exiliados españoles en Costa Rica. El avance del nacional-socialismo, impulsado por Adolf Hitler, y la posibilidad del dominio mundial alarmaron al biólogo español:

América ha podido vivir hasta ahora alejada del estruendo de las batallas y de la destrucción y muerte que caracterizan a los bárbaros métodos utilizados por el nacismo y sus satélites. El aislamiento no ha permitido que se dé el Nuevo Continente exacta cuenta de los peligros que le acechan y de los resultados catastróficos que traería consigo la victoria hitlerista. Por ello la primera tarea que se plantea es el de enseñar la verdad a todos aquellos que, por desconocimiento de la realidad o por falta de cultura política, pueden ser inconscientemente un elemento peligroso a manos de los agentes de la quinta columna.

Hay que pensar en que todos debemos ser combatientes y estar preparados para empuñar las armas si fuera necesario. ${ }^{29}$

29 Rafael de Buen Lozano, "El carácter de la actual contienda (2)”, en Repertorio Americano, núm. 931, 1942, pp. 45 y 46.
La idea de empuñar las armas fue una noción que también compartió Víctor Lorz. Según el profesor español, una de las razones que favoreció la derrota de la Segunda República fue precisamente la falta de armamento y de capacitación militar. En un ensayo titulado "Recuerdos y esperanzas", Víctor Lorz elogia el carácter idealista de los filósofos e intelectuales que crearon la República en 1931, pero desaprueba la falta de experiencia militar que tuvo la península para enfrentar a los sublevados. En el ensayo, se expresa la esperanza de la creación de una tercera República más justa y democrática, pero también menos inocente:

Y aprendamos para el futuro. Que no nos cojan otra vez de primos Para que, cuando amanezca la tercera República, que sea en buena hora democrática, cada vez más democrática, más del pueblo, todo para el 'pueblo. Que venga acompañada de todos los dones excelsos: el cuerno de la abundancia como Pomona, y los resplandores del espíritu, como Minerva. Pero que no sea tonta otra vez. Que en los rincones del Olimpo no deje olvidada las armas. Y que traiga bajo el brazo su casco y su lanza como la diosa griega. ${ }^{30}$

30 Víctor Lorz y Lizárraga, "Recuerdos y esperanzas", en Repertorio Americano, núm. 936, 1942, pp. 122 y 123. 
El médico español Rafael Ruano Riesgo también publicó en Repertorio Americano un discurso pronunciado en el Colegio de San Luis en Cartago, Costa Rica, en el cual expresaba su opinión sobre la guerra de España y sus consecuencias en el conflicto bélico mundial. Ruano hacía especial énfasis en cuál debía ser la conducta y el deber de los refugiados españoles en el exilio:

Es un deber para todo republicano español y para todo hombre honrado, proclamar en voz alta, allí donde se encuentre, la verdad sobre los motivos de la guerra española y la verdad sobre el exilio español. Es un deber sagrado para todo republicano español y para todo hombre libre del mundo, hacer ver al resto de la humanidad que los republicanos españoles lucharon ardientemente por un mínimo de libertades burguesas y no por la implantación de ningún régimen comunista. ${ }^{31}$

Como hemos analizado hasta el momento, los ensayos escritos por los exiliados españoles van dirigidos a explicar los acontecimientos de la Guerra Civil y la situación que vivía España a nivel

31 Rafael Ruano Riesgo, "La guerra de España y la situación política europea”, en Repertorio Americano, núm. 961, 1943, pp. 144 y 145. internacional. Los ensayos expresan en general una firme convicción en un nuevo orden político y moral. La determinación de dar continuidad en el exilio a los valores republicanos defendidos durante la Guerra Civil tiene que leerse como una acción emprendida en contra de los que a nivel internacional rechazaban las ideas progresistas y democráticas de la Segunda República.

Ahora bien, lo que tal vez se eche de menos en las colaboraciones de los exiliados es la referencia explícita a Costa Rica. Los ensayos, como hemos señalado, en general giraban en torno a la problemática española. Sin embargo, los acontecimientos políticos en el país centroamericano también tuvieron un sino trágico. En 1948, se desata la guerra civil, mejor conocida como la Revolución del 48. El conflicto bélico (marzo a mayo de 1948) fue el reflejo del nuevo alineamiento de fuerzas sociales y políticas en diversos sectores de la sociedad costarricense. De estos hechos surgen figuras tan importantes para el desarrollo de la política centroamericana y caribeña como José Figueres. De ahí que sea tan sintomático el silencio y la distancia que en materia política mantuvieran los exiliados.

No obstante, y como se ha demostrado en ciertas investigaciones sobre el exilio, 
"una de las consecuencias más trágicas de vivir y trabajar dentro de una comunidad nacional que no es la propia es una agudización de la frontera entre el pensamiento y la acción o, en el caso del intelectual entre las ideas y la participación política”. ${ }^{32}$ De esta forma, los refugiados españoles en Costa Rica desarrollaron un perfil intelectual vinculado a un tema muy concreto y específico: la problemática de España y las consecuencias del fascismo en Latinoamérica. En las reflexiones de los colaboradores españoles la política del país de acogida quedaba implícitamente censurada.

Con todo, y pese a la distancia que mantuvieron en lo referente a la política costarricense (y quizás por esa misma razón), los exiliados se destacaron en sectores como la educación y la salud. Un buen ejemplo de la estabilidad laboral, social y económica que los desterrados experimentaron al llegar a Costa Rica es el testimonio de Rafael de Buen Lozano; él escribió a su hija desde San José, informándole de su situación en el país centroamericano:

Sigo mis trabajos como siempre, además de mi labor en la Universidad y en salubridad, me estoy

32 Sebastián Faber, "Silencios y tabúes del exilio español en México: historia oficial vs historia oral", en Espacio, Tiempo y Forma, serie V, Historia Contemporánea, t. 17, 2005, pp. 373-389. ahora ocupando de cuestiones de pesca y también tengo que dedicar mucho tiempo a los trabajos relacionados con nuestra lucha en relación con España. Colaboro con todas las asociaciones antitotalitarias, en las organizaciones de republicanos españoles. De manera que no tengo ni un momento libre. También recibo muchas revistas y periódicos nuestros, que leo con el interés que puedes figurarte en la dicha de estar enterado de todo lo que se hace en América.

No me ha sentado mal mi instancia en estas tierras, desde luego me he repuesto mucho desde que llegue, después de la guerra en España y las fatigas en Argelia, necesitaba un período de buena alimentación y la tranquilidad. ${ }^{33}$

La cómoda estadía de Buen Lozano en Costa Rica, e incluso la libertad que tuvo para realizar trabajos propagandísticos a favor de la República fue un hecho generalizado en la comunidad de los refugiados. Por ejemplo, el doctor Rafael Ruano Riesgo fue el jefe de la Unidad Sanitaria de Tres Ríos, jefe de las sucur-

33 Arturo Taracena, "Rafael de Buen Lozano: el periplo americano de un exiliado republicano español", Cuadernos Intercambio sobre Centroamérica y el Caribe, vol. 12, núm. 2, 2015, pp. 101-115. 
sales Puntarenas y Limón del Seguro Social, y secretario médico de la Dirección Médica. Asimismo Víctor Lorz y Lizárraga trabajó como profesor de distintas materias en la Universidad Nacional. ${ }^{34}$

Como hemos visto, Repertorio Americano fue una revista concebida como un lugar de diálogo entre diversos escritores de Hispanoamérica; de ahí la relevancia del tema español durante la década de los años cuarenta.

\section{Consideraciones finales}

La revista Repertorio Americano se convirtió en un vínculo fundamental para la formación de una comunidad intelectual americana. En este sentido, coincidimos con Mario Oliva cuando comenta que: "la obra de García Monge en su conjunto y en particular Repertorio Americano creó un campo cultural propio formado por un modo de producir, circuitos y redes de circulación y una recepción o consumo que asemeja a un abanico desplegado que la hace un universo propicio para el estudio de una época". ${ }^{35}$

34 Véase Julián, Amo y Charmion, Shelby, La obra impresa de los intelectuales españoles en América (1936-1945), California, Standford University Press, 1959.

35 Mario Oliva Medina, "Joaquín García Monge: el editor continental”, VII Congreso Inter nacional de Estudios Latinoamericanos, 2003, p. 20, http://www.repositorio.una.ac.cr/
Sin duda, los casos estudiados en el presente análisis dan un perfil particular a la organización y proyecto cultural de Joaquín García Monge. Las redes que estos escritores, diplomáticos y exiliados generaron entre diversos sectores del campo cultural y político hispanoamericano refleja una imagen específica y compleja de la década de 1940. Las redes y circuitos intelectuales que se generaron en torno de Repertorio Americano sin lugar a dudas tuvieron un impacto significativo en las relaciones políticas y culturales de México y Costa Rica.

Por una parte, las colaboraciones de Vicente Sáenz en Repertorio Americano, son elementales, sobre todo si tenemos presente que el destierro o exilio es un mecanismo de exclusión institucional de aquellos sujetos que disienten de la política vigente y que actúan como figuras esenciales en la opinión pública de determinado país. ${ }^{36}$ Repertorio Americano fungirá entonces como un espacio simbólico de confluencia entre el exilio costarricense en México, algunas de las figuras más emblemáticas del campo cultural mexicano y los miembros más destacados de la sociedad cultural y política de Costa Rica. Estos escritores

bitstream/handle/11056/2883/recurso_971. pdf? sequence $=1$ \& is Allowed $=y$.

36 Luis Roniger y Mario Sznajder, La politica del destierro y el exilio en América Latina, traducción de Lucía Rayas, México, FCE, 2013. 
constituyen una comunidad intelectual que tiene particular importancia en la formación de la opinión pública en Centroamérica y México durante la década de los años cuarenta.

En este punto conviene señalar la importancia que adquiere la revista para la circulación de ideas, pensamientos y polémicas en el campo cultural y político del exilio costarricense y español. De ahí que resulte pertinente la muy aguda observación de Ángel Rama sobre la necesidad que siente el escritor exiliado de dirigirse a públicos distintos, y el desafío que ello supone. En el libro La riesgosa navegación del exiliado, Rama distinguía tres públicos:

El escritor exiliado funciona en relación a tres públicos potenciales que por familiares que sean se encuentran en distintas circunstancias: el público mayoritario del país o cultura en el cual se encuentra instalado provisoriamente; el público también amplio de su país de origen al que aspira a continuar hablando, no empece las trabas que imponen las dictaduras para la circulación de su mensaje; el público de sus compatriotas que integran el pueblo de la diáspora, el cual no puede asimilarse simplemente al del propio país de origen por las nuevas situaciones que está viviendo. Es posible optar exclusivamente por uno de ellos pero lo propio de esta ubicación del escritor exiliado es el intento de conjugar los distintos públicos, que se traduce por su intento de hablar al mismo tiempo a todos ellos, lo que fatalmente habrá de reflejarse en la composición de su obra y será facilitado o entorpecido por el género que práctica. ${ }^{37}$

De modo que las colaboraciones de los exiliados establecieron simbólicamente un circuito de lectura que abarca Costa Rica, España y México. Todavía queda en el tintero analizar las consecuencias y el impacto que estas lecturas generaron en las sociedades antes aludidas.

El caso de Carlos Jinesta Muñoz también muestra el espacio de diálogo que la revista pretendía instaurar entre distintos intelectuales de todo el orbe hispanoamericano. Pese a su militancia política, el diplomático pudo distanciarse de sus credos ideológicos y mantener en sus publicaciones un tono de solidaridad e igualdad americana.

37 Ángel Rama, La riesgosa navegación del escritor exiliado, selección y prólogo de Jorge Ruffinelli, Montevideo, Arca, 1995, p. 242. 
Por otra parte, al reconstruir el panorama político y cultural entre España y Costa Rica durante la década de los años cuarenta, se descubre un esquema político muy polarizado: por un lado, la postura de neutralidad con respecto al conflicto peninsular, y, por otro, la actitud que en la práctica tomaron los distintos gobiernos costarricenses. Sin embargo, y pese al limitado número de exiliados que llegaron al país centroamericano, cada uno de ellos disfrutó de una estabilidad laboral y económica. La llegada de los refugiados políticos a Costa Rica contó con una acogida favo- rable en las páginas de Repertorio Americano. La revista se consolidó como una de las plataformas más importantes en Centroamérica a favor de la causa republicana en el exilio.

Repertorio Americano, tal como lo precisaba el propio Joaquín García Monge, se convirtió en un vínculo fundamental para la formación de una comunidad intelectual americana. Las redes de sociabilidad se extendieron fuera de las fronteras nacionales y la revista se convirtió en un foro transnacional 